\title{
Digital Education of Rural India to Impact Rural Economy
}

\author{
Bella Thomas $^{1}$, S. Senith ${ }^{2}$, A. Alfred Kirubaraj' ${ }^{2}$ S.R. Jino Ramson ${ }^{3}$ \\ ${ }^{1}$ Research Scholar, Karunya Institute of Technology and Sciences (deemed to be University), ${ }^{2}$ Assistant Prof., \\ Karunya Institute of Technology and Sciences (deemed to be University), ${ }^{3}$ School of Engineering Technology, \\ Purdue University, Indiana-47907, USA
}

\begin{abstract}
Education plays an important role within the development of people thereby influencing the growth of the state. Education is one among the necessary sectors within the economy that had brought revolutionary changes within the recent times. Republic of India that was once thought-about as majorly associate in nursing agricultural economy is currently developing in numerous sectors at a quicker rate.

However, the evolution data of knowledge and technology has created a divide between the urban and therefore the rural Republic of India despite of globalization. It's thanks to the digitalization in numerous sectors that has taken place across globe. Villages in Republic of India form the backbone of our nation contributory to socio- economic and human resource development of the state. As per 2011 census, nearly sixty eight of the Indian population belongs to geographic area. Though the life within the rural areas is currently connected to cell phones, smartphones, digital TV transmission, however to an oversized extent they're stop from the most stream of urban areas thanks to lack of infrastructure support, poor property, language barriers particularly within the education sector. Digital technology makes life easier for each educators and students. So as to rework into a Digital India, it's to develop the facilities of rural little villages beside sensible cities in Republic of India.
\end{abstract}

Results and Conclusions: This paper tries to debate regarding the digital tools to be developed in rural areas in a reasonable manner and therefore the core elements of Digital technology likewise because the future scope and challenges of a rural society in moving towards Digital education.

Keywords: Digital Education, Rural areas, web facility, Digital tools, generation Z.

\section{Introduction}

The educators' of Republic of India has created several eminent persons within the country. a toddler might forget his or her subjects however will always remember his teacher. Yes, the students' future is formed by the teachings of his guru. It's the World Health Organization build ministers, doctors, engineers etc.

\section{Corresponding Author:}

\section{S. Senith}

Assistant Prof., Karunya Institute of Technology and Sciences (deemed to be University)

e-mail: senith.seni@gmail.com
In many ways Rural Republic of India has benefitted from the developments in science and technology directly likewise as indirectly but with the emergence of digitalization rural Republic of India continues to be insulation behind digital infrastructure and digital skill which impact the economy of the country. There has been a known observation that was created by the daddy of the state a few years ago that still holds true that claims, "Villagers comprise the core of Republic of Indian Society and conjointly represent the important India. And as our country progresses digitally and technically it's to confirm that awareness of Digital skill is being provided to the lots of rural Republic of India in such the simplest way that may scale the agricultural economy. These days' digital devices have become a desire instead of a wish for the folks. Survival while 
not web and smartphone or computers will build any individual tough to maneuver within the quick paced world.

Village's extremely obsessed with agriculture sector and really less attention is paid in education. Considering the high rise of population in rural sector villager's interest in education has been supported by the govt. through numerous facilities like free middle day meal, books, scholarships and different incentives. On the opposite hand the govt. is additionally that specialize in raising the standard of education. Government is attempting many initiatives for raising the standard of education realizing the issues of poor infrastructure, web property, absence etc. Sincere initiatives are place up to boost the village way in par with the urban population. Villagers terribly poor in deciding downside determination and reasoning and analytical thinking talents. Poverty, state and illiteracy continue to be gift. Thus the most reasons for these are strictly lack of quality education and a lot of significantly steering towards learning. Rural students are quite energetic, enthusiastic and arduous operating thus if target-hunting within the right direction the expansion of the village can happen mechanically.

Rural Population and Issues: India could be a home to almost 430 million kids within the cohort between $0-18$ years within the country. These kids being the longer term of our nation becomes imperative to produce necessary mean that to understand and alter use of their potential by providing necessary means that to uplift their quality of education. Hence forward a progressive education system must be channelized to guide their path which may address prevailing considerations of lack of qualified lecturers, inadequate fashionable teaching materials, that have an effect on the standard of education.

One of the common issues two-faced within the rural sector is that the large quantitative relation of rural-urban registration in faculties that 7:5 nearly sixty per cent of the agricultural students lack reading skills despite improvement within the Teacher pupil quantitative relation which rose from thirty two in 2009-10 to 24 in 2015-16. But single teacher faculties in rural places continue to be a significant concern in several rural components of the country. Recent numbers suggests that the amount of single teacher faculties in Republic of India account for ninety seven, 273 i.e. 8.8 per cent of the overall faculties within the country These problems make to lack of quality education and high drop outs in rural faculties in Republic of India. ${ }^{10}$

Therefore to combat the scholar teacher quantitative relation within the times the employment digitalized technology can facilitate in mitigating the same considerations. Education are often digitalized within the rural faculties by giving providing multimedia system teaching tools and interesting students through digitalized teaching tools like sensible boards, LCD screens Videos, to show them totally different ideas. Digital Media can modify the lecturers to deliver their sessions remotely across many locations. As per the information in 2016 nearly nine, 07,585 posts for lecturers are lying vacant in elementary faculties and one, 06,906 posts in secondary faculties. ${ }^{6}$

One of the foremost problems found within the rural students was lack of interest that accounted for twenty. 24 per cent of the college kids. With the interactive learning tools will build students fascinating to attend the faculties' often. ${ }^{4}$

Leverage of Digital Emotional Intelligence through Digital Technology: In order to supply quality education within the rural place the technological development exposes new potentialities and learning ways that are continually being challenged within the academic system. Thus it's essential to develop digital emotional intelligence with the offered digital technologies. Some lecturers feel that technology will erase their role, however indeed technology will ne'er scale back the role of an educator. Thus digital emotional intelligence and digital technologies must be leveraged to make a much better impact within the academic institutes of Rural Republic of India.

Review Literature: From the review of literature it's clear that analysis has been allotted in emotional intelligence textile the wants of scholars. Thus keeping this the current study has been allotted.

Gopal, D.H. Jagadeesh (2018) ${ }^{1}$, rumored the extent of relationship between emotional intelligence and burnout among teacher educators. The author disclosed that to scale back the teachers' burnout and to boost the amount of the teachers' engagement, Emotional intelligence is vital in terms of teaching profession, since it might predict a much better angle toward work and a lower probability to expertise burnout.

Chitra Krishnan, Richa Goe et al., (2017)², studied 
the link of expertise and age of a private on the amount of emotional intelligence. Author found perception and therefore the level of emotional intelligence in an exceedingly person on the idea of his/her cohort and gender. Results of the Z-test shows that respondents take age teams differ in emotional intelligence except between age teams of 25-35 and on top of fifty five and all over those females have higher emotional intelligence than males.

\section{Success of Emotional Intelligence in on-line} Learning: The writers assessed the use of composed words because the essential variety of correspondence, while not nonverbal signs and noticed that: "understudies' neglected needs for human contact, absence of selfinspiration, or sentiments of disconnection will stop accomplishment in on-line courses" (Berenson, Boyles and Weaver, 2008). These variables are usually sincerely based mostly responses that has to be perceived and oversaw if understudies got to work with success within the on-line condition. This is not to scale back the need for these characteristics; in any case, the emotions got to be managed initial with the goal that the fundamental problems are often attended.

A recent report titled, affiliation between Understudies' fervent information, Social Bond and Communications in internet based mostly Learning, is one among few examinations that thought-about the difficulties connected with an internet schoolroom condition.

\section{There are 3 key focuses that attended feelings and recognition:}

1. "The restricted ecological ability to check feelings in web learning might convey a lot of noteworthy enthusiastic separation to understudies World Health Organization has low capability to check feelings."

2. "It is tough to check feelings in an exceedingly internet based learning condition thanks to the accentuation on content based correspondence, that doesn't need outward look."

3. "It may well be all the lot of attempting for folks with a lower capability to check feeling to grasp others' sentiments in on-line things." These 3 hindrances happen often once understudies at first, start an internet category or build a progress from Associate in Nursing on-ground to an internet scenario. The motivation behind why it's hard for understudies to check feelings is that they need not engineered up Associate in nursing adjusted variety of fervent information.

Creating Virtual fervent Insight: Using Goleman's model of fervent insight, he provides a 3 stage method that adjusts it to be used by understudies within the online schoolroom.

Stage One: look into and traumatize your fervent standing

Before we have a tendency to begin to figure within the on-line schoolroom, think about the dimension of fervent heedfulness and readiness for operating during this innovation based mostly condition. Begin by leading a private self-check and build these inquiries: however would I feel at the current time? Am I ready to start out category currently and partake? Do I actually have considerations, dissatisfactions, or diversions that I actually have to address? Likewise we are able to take enthusiastic insight appraisals, as an example, the one offered by the institution for welfare and Human Potential, check your combining weight. What we want to make is our enthusiastic heedfulness, as a ways for overseeing however we have a tendency to feel and dominant any negative feelings.

Stage Two: Take Associate in nursing interest for all intents and functions with a Reason

Social contribution in an internet category contains of virtual associations in an exceedingly virtual area. Understudies rely on recognitions, which thus build feelings. Composed correspondence has the flexibility to adapt or de-refine the educational procedure, dependent on the interpretation of the messages. Composed messages and posts speak and convey a "tone" in lightweight of the mechanics of the reaction and therefore the word selections used. For example, poor writing system and syntax, or improper formulation, might prompt a negative observation regarding oneself - that likewise produces Associate in nursing enthusiastic reaction. A virtual scenario needs intentional associations, taking under consideration what we have a tendency to compose and the way it's introduced. It prescribed build posts disconnected initial and at that time scan them thus anyone would possibly hear to make your mind up however they may be seen. This can prompt advancement of virtual, social heedfulness. 
Stage Three: build a Social closeness: Relationship the board in an exceedingly virtual scenario contains of finding new method for interfacing with, distinctive with and participating in discussions. Just about each on-line category includes a dialog board necessity, in order that could be a strategy for creating a scholastic network. There's an opportunity to post a presentation, which is able to modify professional to finish up a "genuine" individual to the category. What are often done is to make and traumatize our virtual character. We won't management the observations or enthusiastic responses of schoolmates; however, we can build up the image delineated through the posts. Ceaselessly choose accent that's affordable for a erudite scenario and abstain from formulation, as an example, slang, content informing shortened forms, or composing all told ace. The advancement of a positive image is to boot advantageous in light-weight of the actual fact that it influences operating associations with totally different understudies and teacher.

The online schoolroom could be a dynamic, intuitive condition that's created necessary through the character of posts and messages lecturers will build. Like another schoolroom condition, sentiments ought to be surveyed and fervent responses oversaw, thus it will connect with success with totally different cohorts. Once virtual fervent information is made educators approach the educational procedure equitably and keep one's distance from abstract reactions that build boundaries to correspondence.

\section{Affordable Digital Tools for Rural College lecture rooms}

There are differing types of various advances as of currently will use in rustic lecture rooms to urge to the net administrations. as an example,

(i) Class Website: a straightforward technique to point out your understudy's work is to create a website page supposed for category. Once a web site page is planned, specialists will post prep assignments, understudy work, adages, question and answer contests, therefore considerably a lot of.

(ii) Blogs: It allows the understudies to stay up a running discourse, as an example, a diary, musings, thoughts and assignments that to boot accommodate understudy remark and reflection.

(iii) Wikis are a lot of gathering focused to modify numerous people from the gathering to change a solitary report and build an extremely communitarian and cautiously altered completed item.

(iv) Wireless schoolroom mouthpieces: Uproarious lecture rooms are every day by day event and with the help of amplifiers, understudies will hear their educators all the a lot of plainly. The advantage for instructors is that they nevermore lose their voice by the day's finish.

(v) Interactive Whiteboards: Associate in nursing intelligent whiteboard that offers contact management of laptop applications. This upgrade the involvement within the schoolroom by demonstrating no matter is often on a laptop screen. This guides in visual learning, likewise because it is intelligent, therefore the understudies will draw, compose, or management photos on the intuitive whiteboard.

(vi) Online Media: Gushed video sites are often wont to upgrade a schoolroom exercise. Instructive advancements are planned to reinforce coaching. a little of the bonded blessings are recorded underneath: I) easy to-get to course materials. Lecturers will post the course material or vital knowledge on a course website, which suggests understudies, will learn right away and space they lean toward and may get the examination material quickly. ii) Heading to understudies. iii) Understudy inspiration: laptop based mostly steering will offer moment input to understudies and clarify right answers. iv) Rules in learning v) Wide support: Learning material are often used for long separation learning and are hospitable a lot of intensive cluster of onlookers. vi) Increased understudy composing v) Logical, numerical, vital thinking aptitudes vi) Separated Guidance: Instructive innovation provides the thanks to focus on dynamic understudy cooperation and to exhibit separated addressing procedures.

(vii) Data regarding the innovation, occupations, degrees and openings. ${ }^{11}$

Going disconnected-sinking handiness problems: Other than having the quality eLearning edges, mLearning gets arrangements which allow about to the substance disconnected in an exceedingly protected manner. This functions the problem of not having consistent internet handiness. The data is shipped back to the server once related to the net, on these lines simply following the course advancement and gathering input. 


\section{Conclusion}

Indian rural schools' problems may well be unraveled by leading edge innovations and devices. Work space and capability virtualization causes the country understudies to urge the investigation, information, subject and learning materials. Mists registering to boot assist the understudy with obtaining any learning materials over internet. The Moodle instruments serves to provincial understudies in intelligent learning and to urge legitimate bearings. Totally different innovations bolster provincial college understudies from multiple points of read. Propelled device and advancements provides correspondence master and quality materials. It takes care of the problems like I) Absence of import coaching and fewer enough examination materials ii) Lack of specialists direction in learning iii) Not sharing the data regarding in progress patterns and openings iv) Absence of presentation to current world and v)Lack of legitimate direction towards seeking once occupation organized courses vi) Absence of on-request information so forth.

For what reason improve grades?: Execution patterns uncover that urban students perpetually secure most well-liked evaluations over their rustic partners. It's not gauge that influences their execution, but the assets and openings accessible to them. Once more, we won't state that instructing is certainly not associate in nursing ennobling business. There are extremely energetic instructors out there to possess any reasonably impact. In any case, poor compensation and deficient getting ready are exhausting.

Innovation, on its half, will probably unquestionably influence the character of instruction and what is more to interrupt the advanced separation tormenting our framework.

\section{Conflict of Interest: Nil}

\section{Source of Funding-Self}

Ethical Clearance: Approved by SRC Committee at Department of Management Studies.

\section{References}

1. Gopal, D.H. Jagadeesh: Relationship between Emotional Intelligence and Burnout among Teacher Educators: The International Journal of Indian psychological science; 2018.

2. Priyavrat Mishra. A Study of the Factors of Emotional Intelligence. IOSR Journal of Business and Management. 2018.

3. Nina Barłożek: Teachers' emotional intelligencean important part within the learning process: Opole University.

4. https://www.indiatoday.in/education-today/ featurephilia/story/india-rural-educationproblems-958214-2017-01-31

5. International Journal of laptop Applications (0975 - 8887) Volume 36- No.10, Dec 2011

6. http://www.forbesindia.com/blog/education/ digital-education-among-students-in-rural-areas/

7. https://www.onlinecollegecourses. com/2012/05/21/online-students-need-virtualemotional-intelligence/

8. Educational data system in Republic of India and its Limitations: Suggestions for Improvement http:// www.educationforallinindia.com/page121.htm

9. On the issues two-faced by Indian education system http://www.indiaeducationreview.com/vc-desk/ problems-faced-indian-education-system- 0

10. Ministry of rural development, government of Republic of India http://rural.nic.in/

11. Journal of yank Indian Education Volume ten no 1 http://jaie.asu.edu/v10/V10S1 eig.html 